\title{
SCO-267, a GPR40 Full Agonist, Improves Glycemic and Body Weight Control in Rat Models of Diabetes and Obesity ${ }^{[}$
}

\author{
Hikaru Ueno, Ryo Ito, Shin-ichi Abe, Mitsugi Ookawara, Hirohisa Miyashita, Hitomi Ogino, \\ Yasufumi Miyamoto, Tomoki Yoshihara, Akihiro Kobayashi, Yoshiyuki Tsujihata, \\ Koji Takeuchi, Masanori Watanabe, Yukio Yamada, Tsuyoshi Maekawa, Nobuhiro Nishigaki, \\ and (1) Yusuke Moritoh
}

Takeda Pharmaceutical Company Limited, Kanagawa, Japan (H.U., R.I., H.M., H.O., Y.Mi., T.Y., Y.T., K.T., N.N.); and SCOHIA PHARMA, Inc., Kanagawa, Japan (S.A., M.O., A.K., M.W., Y.Y., T.M., Y.Mo.)

Received December 26, 2018; accepted April 1, 2019

\begin{abstract}
The GPR40/FFA1 receptor is a G-protein-coupled receptor expressed in the pancreatic islets and enteroendocrine cells. Here, we report the pharmacological profiles of (3S)-3-cyclopropyl3-\{2-[(1-\{2-[(2,2-dimethylpropyl)(6-methylpyridin-2-yl)carbamoyl]5-methoxyphenyl\}piperidin-4-yl)methoxy]pyridin-4-yl\}propanoic acid (SCO-267), a novel full agonist of GPR40. $\mathrm{Ca}^{2+}$ signaling and insulin and glucagon-like peptide-1 (GLP-1) secretion were evaluated in GPR40-expressing $\mathrm{CHO}$, MIN6, and GLUTag cells. Hormone secretions and effects on fasting glucose were tested in rats. Single or repeated dosing effects were evaluated in neonatally streptozotocin-induced diabetic rats (N-STZ-1.5 rats), diet-induced obese (DIO) rats, and GPR40-knockout $\left(\right.$ Ffar1 $\left.^{-/}\right)$mice. Treatment with SCO-267 activated $\mathrm{Gq}$ signaling in both high- and low-FFAR1-expressing $\mathrm{CHO}$ cells, stimulated insulin secretion in MIN6 cells, and induced GLP-1 release in GLUTag cells. When administered to normal rats, SCO-267 increased insulin, glucagon, GLP-1,
\end{abstract}

glucose-dependent insulinotropic peptide, and peptide $Y Y$ (PYY) secretions under nonfasting conditions. These results show the full agonistic property of SCO-267 against GPR40. Hypoglycemia was not induced in SCO-267-treated rats during the fasting condition. In diabetic N-STZ-1.5 rats, SCO-267 was highly effective in improving glucose tolerance in single and 2-week dosing studies. DIO rats treated with SCO-267 for 2 weeks showed elevated plasma GLP-1 and $P Y Y$ levels, reduced food intake, and decreased body weight. In wild-type mice, SCO-267 induced GLP-1 secretion, food intake inhibition, and body weight reduction; however, these effects were abolished in Ffar1 ${ }^{-/-}$mice, indicating a GPR40dependent mechanism. In conclusion, SCO-267 stimulated islet and gut hormone secretion, improved glycemic control in diabetic rats, and decreased body weight in obese rats. These data suggest the therapeutic potential of SCO-267 for the treatment of diabetes and obesity.

\section{Introduction}

The GPR40/FFA1 receptor, a G-protein-coupled receptor (GPCR), couples predominantly with the $\mathrm{Gq} / 11$ protein, promoting phospholipase $\mathrm{C}$-dependent hydrolysis of phosphatidylinositol 4,5-bisphosphate into diacylglycerol and inositol 1,4,5-triphosphate (Ghislain and Poitout, 2017). This, in turn, increases intracellular $\mathrm{Ca}^{2+}$ concentrations ( $\mathrm{Li}$ et al., 2018). Medium-to-long chain fatty acids activate intracellular $\mathrm{Ca}^{2+}$ responses in GPR40-expressing cells, demonstrating that they are natural GPR40 ligands (Briscoe et al., 2003; Itoh et al., 2003; Kotarsky et al., 2003). GPR40 is expressed in

The present study was conducted with financial support from Takeda Pharmaceutical Company Limited and SCOHIA PHARMA Inc.

H.U., R.I., H.M., H.O., Y.Mi., T.Y., Y.T., K.T., and N.N. are/were employees of Takeda Pharmaceutical Company Limited. S.A., M.O., A.K., M.W., Y.Y. T.M., and Y.Mo. are employees of SCOHIA PHARMA, Inc. https://doi.org/10.1124/jpet.118.255885.

S This article has supplemental material available at jpet.aspetjournals.org. pancreatic $\beta$-cells and intestinal endocrine cells, and its activation stimulates insulin and incretin secretion (Mancini and Poitout, 2013; Pais et al., 2016). Since insulin and incretin are pivotal for glycemic control (Nauck and Meier, 2018), GPR40 activation is considered a novel option for treating diabetes (Eleazu et al., 2018).

To date, several synthetic compounds targeting GPR40 have been developed, and the structure-activity relationships of these agonists have been investigated (Defossa and Wagner, 2014). Importantly, fasiglifam (Negoro et al., 2010; Tsujihata et al., 2011; Ito et al., 2013), a GPR40 agonist, has been shown to significantly improve glycemic control in patients with type 2 diabetes (Burant et al., 2012; Kaku et al., 2013, 2016); however, fasiglifam testing was voluntarily terminated in phase 3 clinical trials because of possible adverse effects on the liver (Wolenski et al., 2017). Proof of concept of a GPR40 agonist to treat diabetes has attracted considerable attention owing to its potential as a valuable drug target. Concurrently, fasiglifam was demonstrated as a

ABBREVIATIONS: $\mathrm{AUC}_{0-24 \mathrm{~h}}$, area under the curve from zero to 24 hours; $\mathrm{BSA}$, bovine serum albumin; DIO, diet-induced obese; $E_{\text {max }}$, maximum effect; GIP, glucose-dependent insulinotropic peptide; GLP-1, glucagon-like peptide-1; GPCR, G-protein-coupled receptor; N-STZ, neonatally streptozotocin-induced; PYY, peptide YY; WT, wild type. 
GPR40 partial agonist based on $\mathrm{Ca}^{2+}$ mobilization in GPR40expressing cells (Yabuki et al., 2013). Additional studies identified a novel series of GPR40 agonists with different profiles from partial agonists. A seminal study demonstrated that (3S)-3-cyclopropyl-3-(3-\{[3-(5,5-dimethylcyclopenten-1-yl)4-(2-fluoro-5-methoxyphenyl)phenyl]methoxy\}phenyl)propanoic acid (AM-1638) has full agonistic activity toward GPR40, and was more effective in stimulating insulin secretion and improving glucose-lowering efficacy in vivo than partial agonists (Brown et al., 2012; Luo et al., 2012).

Importantly, GPR40 full agonists can activate the enteroendocrine system while stimulating insulin secretion (Luo et al., 2012). Such mechanisms seem highly valuable in developing a novel strategy for treating diabetes. Indeed, glucagon-like peptide-1 (GLP-1) signaling activation has been proven to have beneficial effects, including improved long-term glucose control and decreased incidence of cardiovascular death, in patients with type 2 diabetes mellitus (Nauck et al., 2017). Since GPR40 partial agonists improve glycemic control in patients with diabetes, GPR40 full agonists may provide superior efficacy and additional benefits in patients with metabolic diseases. To date, there has been no report on the clinical efficacy of the GPR40 full agonist. Thus, preclinical efficacy studies including fasiglifam as a comparator would provide important information to develop novel GPR40 full agonists.

Here, we report the pharmacological profiles and efficacy of (3S)-3-cyclopropyl-3-\{2-[(1-\{2-[(2,2-dimethylpropyl)(6-methylpyridin-2-yl)carbamoyl]-5-methoxyphenyl\}piperidin-4-yl) methoxy]pyridin-4-yl\}propanoic acid (SCO-267), a novel GPR40 full agonist (Aida et al., 2015). Its in vitro efficacy was evaluated using cell models, and its effect on islet, gut hormones, and glycemic control was evaluated in rat models. SCO-267's contribution to body weight reduction was evaluated in obese rats and GPR40 knockout mice. Finally, we compared some key effects induced by SCO-267 to fasiglifam.

\section{Materials and Methods}

Materials. All reagents were purchased from FUJIFILM Wako Pure Chemical Corporation (Osaka, Japan), Sigma-Aldrich (Tokyo, Japan), or Cayman Chemical (Michigan) unless otherwise indicated. SCO-267, fasiglifam, and AM-1638 were obtained from SCOHIA PHARMA, Inc., and Takeda Pharmaceutical Company Limited. Glimepiride was purchased from FUJIFILM Wako Pure Chemical Corporation. For in vitro studies, compounds were dissolved in dimethylsulfoxide, and for in vivo studies, compounds were suspended in $0.5 \%$ methylcellulose solution (FUJIFILM Wako Pure Chemical Corporation). The dose of each compound was expressed as the free base form.

FFAR1-Expressing CHO Cell Assay. CHO dihydrofolate reductase-deficient cells (clones 104 and 2) stably expressing human FFAR1 (Yabuki et al., 2013) were cultured with minimum essential medium- $\alpha$ (FUJIFILM Wako Pure Chemical Corporation) containing $10 \%$ FBS, $10 \mathrm{mmol} / \mathrm{l}$ HEPES (Thermo Fisher Scientific, Waltham, MA), $100 \mathrm{IU} / \mathrm{ml}$ penicillin, and $100 \mu \mathrm{g} / \mathrm{ml}$ streptomycin in $5 \% \mathrm{CO}_{2}$ at $37^{\circ} \mathrm{C}$. The cells $\left(1 \times 10^{4}\right.$ cells/well) were seeded in 384 -well (blackwalled clear-bottom) culture plates and incubated overnight in 5\% $\mathrm{CO}_{2}$ at $37^{\circ} \mathrm{C}$. After removing the medium, the cells were incubated in $30 \mu \mathrm{l}$ of loading buffer (Hanks' balanced salt solution; Thermo Fisher Scientific) containing $20 \mathrm{mmol} / \mathrm{l} \mathrm{HEPES}, 0.1 \%$ fatty acid-free bovine serum albumin (BSA), 0.08\% Pluronic F127 (CSK-01F; Dojindo, Kumamoto, Japan), $2.5 \mathrm{mmol} / \mathrm{l}$ probenecid (CSK-03F; Dojindo), and $2.5 \mu \mathrm{g} / \mathrm{ml}$ Fluo4 (F311; Dojindo) for 60 minutes in $5 \% \mathrm{CO}_{2}$ at $37^{\circ} \mathrm{C}$. Test compounds of various concentrations were added to the cells and the increase in intracellular $\mathrm{Ca}^{2+}$ concentration was monitored for 180 seconds using the FLIPR Tetra System (Molecular Devices, Tokyo, Japan).

MIN6 Cell Assay. The pancreatic $\beta$-cell line, MIN6, displays features of glucose metabolism and glucose-induced insulin secretion similar to those of normal islets (Miyazaki et al., 1990). MIN6 cells were seeded at $5 \times 10^{4}$ cells/well in 96 -well plates and cultured as described previously (Miyazaki et al., 1990). After discarding the medium, the cells were preincubated for 2 hours at $37^{\circ} \mathrm{C}$ with $100 \mu \mathrm{l}$ of Krebs-Ringer bicarbonate/HEPES buffer $(116 \mathrm{mmol} / \mathrm{l}$ $\mathrm{NaCl}, 4.7 \mathrm{mmol} / \mathrm{K} \mathrm{KCl}, 1.17 \mathrm{mmol} / \mathrm{l} \mathrm{KH} \mathrm{PO}_{4}, 1.17 \mathrm{mmol} / \mathrm{l} \mathrm{MgSO}$, $25 \mathrm{mmol} / \mathrm{l} \mathrm{NaHCO}{ }_{3}, 2.52 \mathrm{mmol} / \mathrm{l} \mathrm{CaCl}_{2}$, and $24 \mathrm{mmol} / \mathrm{l} \mathrm{HEPES}$ ) containing $0.2 \%$ fatty acid-free BSA and $1 \mathrm{mmol} / \mathrm{l}$ glucose. After discarding the buffer, Krebs-Ringer bicarbonate/HEPES buffer containing 1 or $16 \mathrm{mmol} / \mathrm{l}$ glucose, $0.2 \%$ fatty acid-free BSA, and test materials at indicated concentrations was added and the plate was further incubated for 2 hours at $37^{\circ} \mathrm{C}$. After incubation, supernatants were collected from all wells and the insulin concentrations were determined.

GLUTag Cell Assay. GLUTag cells are stable, immortalized, and relatively differentiated murine enteroendocrine cells (Lee et al., 1992), and in this study these cells were seeded at $1 \times 10^{4}$ cells/well in 96-well poly-L-lysine-coated plates. Cells were cultured in Dulbecco's modified Eagle's medium with $10 \%$ FBS, $100 \mathrm{IU} / \mathrm{ml}$ penicillin, $100 \mu \mathrm{g} / \mathrm{ml}$ streptomycin, and $25 \mathrm{mmol} / \mathrm{l}$ glucose. The culture medium was replaced with medium containing $10 \%$ FBS, $100 \mathrm{IU} / \mathrm{ml}$ penicillin, $100 \mu \mathrm{g} / \mathrm{ml}$ streptomycin, and $5.5 \mathrm{mmol} / \mathrm{lglucose}$ prior to overnight incubation. After discarding the medium, KrebsRinger bicarbonate/HEPES buffer containing $10 \mathrm{mmol} / \mathrm{l}$ glucose, $0.2 \%$ fatty acid-free BSA, and the test materials at indicated concentrations was added and the plate was further incubated for 2 hours at $37^{\circ} \mathrm{C}$. The supernatants were collected from all wells and the GLP-1 concentrations were determined.

Plasma Protein Binding. Plasma samples of rats, dogs, and humans were purchased from Charles River Laboratories Japan, Inc. (Kanagawa, Japan), Kitayama Labes Co. Ltd. (Nagano, Japan), and Cosmo Bio (Tokyo, Japan), respectively. In vitro plasma protein binding of SCO-267 in rats, dogs, and humans was evaluated by using liquid chromatography-tandem mass spectrometry following ultracentrifugation.

Animals. All animals were housed in a room with controlled temperature $\left(23^{\circ} \mathrm{C}\right)$, humidity $(55 \%)$, and lighting (lights on between 7:00 AM and 7:00 PM). All animals were allowed free access to standard laboratory chow diet (CE-2; CLEA Japan, Inc., Tokyo, Japan) and tap water. The care and use of animals and the experimental protocols were approved by the Experimental Animal Care and Use Committee of Takeda Pharmaceutical Company Limited and SCOHIA PHARMA, Inc. All experiments were performed according to the guidelines and regulations of Takeda Pharmaceutical Company Limited and Shonan Health Innovation Park. For animal studies, $0.5 \%$ methylcellulose was used as vehicle. All blood samples used in the present study were obtained via the tail vein of animals.

Sprague-Dawley Rat Study. Male Sprague-Dawley rats were obtained from CLEA Japan, Inc. For the hormone secretion experiment in the nonfasted state, 6 -week-old rats were randomized into groups ( $n=6$ ) based on body weight. To evaluate the compound's effect on fasting plasma glucose levels, 8-week-old rats were fasted overnight. Rats were randomized into groups $(n=6)$ based on body weight and plasma glucose. The test materials were orally administered at the indicated doses. Blood samples were collected at indicated time points, and plasma parameters were determined. A fasting plasma glucose range below $70 \mathrm{mg} / \mathrm{dl}$ was considered hypoglycemic (American Diabetes Association, 2018). A pharmacokinetic study was performed using nonfasted 6-week-old male Sprague-Dawley rats $(n=3)$ obtained from Charles River Laboratories Japan Inc.

Neonatally Streptozotocin-Induced Diabetic Rat Study. Male neonatally streptozotocin-induced (N-STZ) diabetic rats were developed via subcutaneous administration of $120 \mathrm{mg} / \mathrm{kg}$ streptozotocin (STZ) to 
Wistar Kyoto rats (RABICS, LTD. Kanagawa, Japan) at 1.5 days after birth (N-STZ-1.5 rats). Neonatally streptozotocin-induced rats were reported to display defects in insulin secretion and action, which in many ways resemble those observed in human diabetic patients (Portha et al., 2003). To evaluate the efficacy of single dosing, 25-week-old N-STZ-1.5 rats were subjected to overnight fasting and randomized into groups $(n=6)$ based on fasting plasma glucose, triglyceride levels, and body weight. The test materials were orally administered 60 minutes before oral glucose loading $(1.5 \mathrm{~g} / \mathrm{kg})$. The effect of an oral dose of AM-1638 on glucose tolerance and its plasma concentration was compared with SCO-267 in a similarly designed experiment using male N-STZ-1.5 rats [32- and 18-week-old for glucose tolerance test $(n=6)$ and pharmacokinetic study $(n=3)$, respectively]. Then, to evaluate the effects of repeated-dosing, 27-week-old N-STZ-1.5 rats (baseline body weight, $373 \mathrm{~g}$ ) were randomized into groups $(n=6)$ based on glycosylated hemoglobin level, plasma glucose concentration, body weight, and food intake. Each group was treated with the indicated test materials once daily for 2 weeks. Following the 2 -week treatment period, the rats were fasted overnight, and the test materials were orally administered at indicated doses 60 minutes before an oral glucose load (1.5 g/ kg). Blood samples were collected at indicated time points and plasma parameters were determined. Following the oral glucose load test, a pharmacokinetic study was performed with the same nonfasted rats. A pharmacokinetic study of $0.3 \mathrm{mg} / \mathrm{kg}$ SCO- 267 and $3 \mathrm{mg} / \mathrm{kg}$ fasiglifam was conducted under the same experimental conditions in 20-week-old male N-STZ-1.5 rats $(n=6)$.

Diet-Induced Obese Rat Study. Male F344 rats aged 29 weeks were obtained from CLEA Japan, Inc., and fed a high-fat diet (D12451M, 45 kcal\%; Research Diets, Inc., New Brunswick, NJ) to induce obesity. At 49 weeks, the diet-induced obese (DIO) rats (baseline body weight, $487 \mathrm{~g})$ were randomized into groups $(n=6)$ based on body fat mass, daily food intake, and body weight. Each group was treated with the indicated test materials once daily for 2 weeks. Blood samples were collected at indicated time points and plasma parameters were determined. Body compositions were<smiles>COc1ccc(C(=O)N(CC(C)(C)C)c2cccc(C)n2)c(N2CCC(COc3cc(C(CC(=O)O)C4CC4)ccn3)CC2)c1</smiles>



D Insulin secretion in MIN6 cells

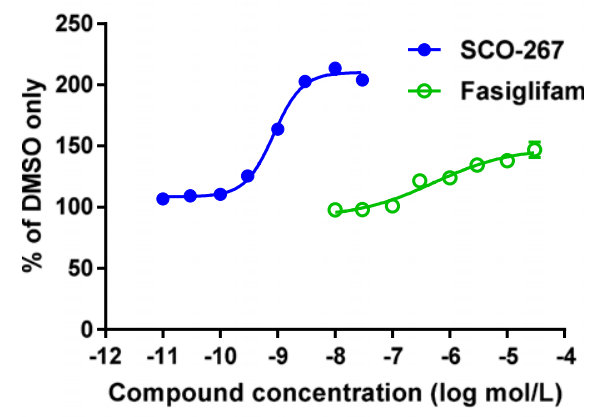

$16 \mathrm{mmol} / \mathrm{L}$ glucose

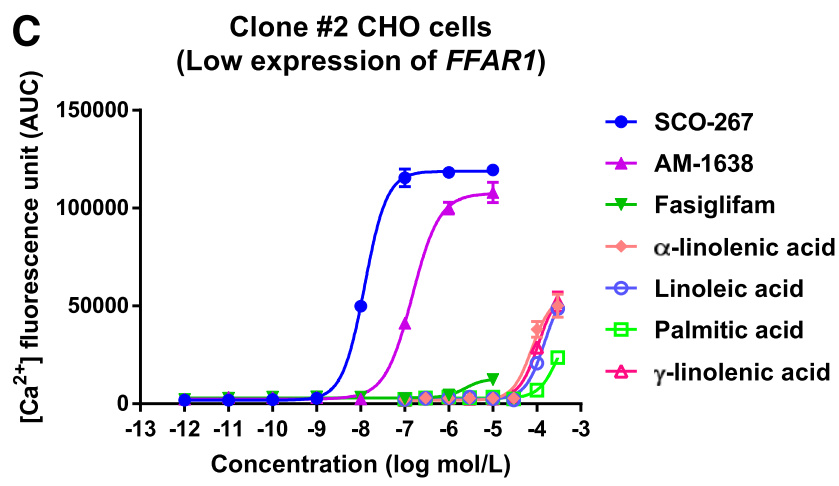

E GLP-1 secretion in GLUTag cells

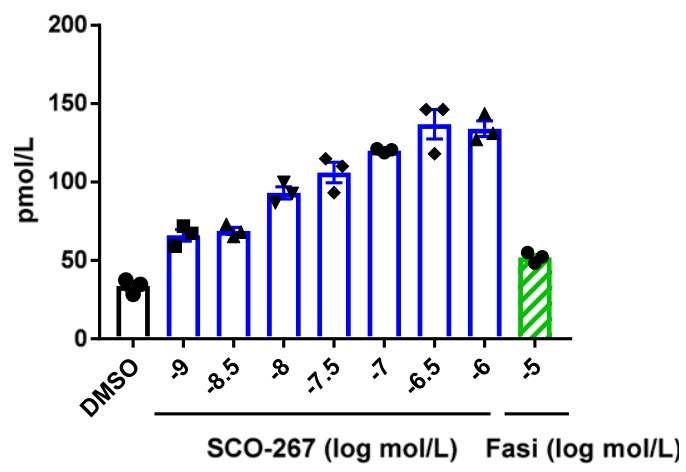

$10 \mathrm{mmol} / \mathrm{L}$ glucose

Fig. 1. Effects of SCO-267 on $\mathrm{Ca}^{2+}$ concentration in FFAR1-expressing CHO cells, insulin secretion in MIN6 cells, and GLP-1 secretion in GLUTag cells. (A) Chemical structure of SCO-267. Intracellular $\mathrm{Ca}^{2+}$ responses against SCO-267 and other agonists in $\mathrm{CHO}$ cells expressing high [(B), clone 104] and low [(C), clone 2] levels of human FFAR1 (mean \pm S.E.M. of quadruplicate wells; similar results were obtained in an independent study). (D) Concentration-dependent insulin secretion response of SCO-267 in MIN6 cells with $16 \mathrm{mmol} / \mathrm{l}$ glucose condition (mean \pm S.E.M. of triplicate wells). (E) Stimulation of GLP-1 secretion in GLUTag cells with $10 \mathrm{mmol} / \mathrm{l}$ glucose condition (mean \pm S.E.M. and individual data of triplicate wells). SCO-267 activated an intracellular $\mathrm{Ca}^{2+}$ response in CHO cells expressing high and low levels of human $F F A R 1$, showing full agonistic potency for GPR40. SCO267 stimulated insulin secretion from MIN6 $\beta$ cells and GLP-1 secretion from GLUTag enteroendocrine cells. Fasi, fasiglifam. 
TABLE 1

$\mathrm{Ca}^{2+}$ influx activity in human FFAR1-expressing CHO cells

\begin{tabular}{|c|c|c|c|c|}
\hline \multirow{2}{*}{ Test Material } & \multicolumn{2}{|c|}{ CHO Cells with High FFAR1 Expression (Clone 104) } & \multicolumn{2}{|c|}{ CHO Cells with Low FFAR1 Expression (Clone 2) } \\
\hline & $\mathrm{EC}_{50}[95 \% \mathrm{CI}]$ & $E_{\max }(\% \gamma$-Linolenic Acid $)$ & $\mathrm{EC}_{50}[95 \% \mathrm{CI}]$ & $E_{\max }(\% \gamma$-Linolenic Acid $)$ \\
\hline & nmol/l & & $n m o l / l$ & \\
\hline SCO-267 & $1.3[0.97-1.7]$ & 125 & 12 [11-14] & 201 \\
\hline AM-1638 & $7.1[5.6-9.2]$ & 110 & $150[120-180]$ & 182 \\
\hline Fasiglifam & 24 [16-37] & 100 & $>1,000$ & 22 \\
\hline$\alpha$-Linolenic acid & $>10,000$ & 110 & $>10,000$ & 93 \\
\hline Linoleic acid & $>10,000$ & 109 & $>10,000$ & 102 \\
\hline Palmitic acid & $>10,000$ & 113 & $>10,000$ & 78 \\
\hline$\gamma$-Linolenic acid & $>10,000$ & 100 & $>10,000$ & 100 \\
\hline
\end{tabular}

CI, confidence interval.

determined after 2 weeks of treatment. GLP-1 and peptide YY (PYY) levels were measured 16 hours after the 15 th dosing and a pharmacokinetic study was performed with nonfasted DIO rats after the 20th drug dosing.

Ffar $1^{-1-}$ Mouse Study. Male Ffar $1^{-/}$and their wild-type (WT) littermates were obtained from RABICS, LTD. (Matsuda-Nagasumi et al., 2013). Ffar $1^{-1-}$ and WT mice were fed a high-fat diet (D12451; Research Diets, Inc.) from the age of 21 weeks. At 29 weeks of age, mice from each strain were randomized into groups based on food intake and body weight (baseline body weight, $40 \mathrm{~g}$ for WT and $41 \mathrm{~g}$ for $F f a r 1^{-1-}, n=6$ ). The test materials were orally administered once daily. After 3 days of dosing, food intake and body weight changes were calculated. GLP-1 levels were measured 1 hour after the fourth dosing of the test materials. A pharmacokinetic study was performed using 10 -week-old male nonfasted C57BL/6J mice $(n=3)$ obtained from CLEA Japan, Inc.

Measurements. Plasma metabolic parameters were measured with an Autoanalyzer 7180 (Hitachi, Tokyo, Japan). Insulin levels were measured using a radioimmunoassay kit (RI-13K; Merck Millipore, Burlington, MA), ELISA kit (MS301; Takara, Shiga, Japan), or alphaLISA (PerkinElmer, Waltham, MA). Plasma total glucosedependent insulinotropic peptide (GIP) levels were determined using an ELISA kit (EZRMGIP-55K; Merck Millipore). Plasma glucagon was measured using a radioimmunoassay kit (GL-32K; Merck Millipore) or ELISA kit (10-1271-01; Mercodia, Uppsala, Sweden). Plasma total GLP-1 was determined by using an ELISA established by Takeda Pharmaceutical Company Limited or a commercially available ELISA kit (299-75501; FUJIFILM Wako Pure Chemical Corporation). Plasma total PYY levels were determined using ELISA (291-73501; FUJIFILM Wako Pure Chemical Corporation) or Rat/Mouse PYY RIA (RMPYY-68HK; Merck Millipore). Body composition was quantified by magnetic resonance imaging to directly measure total body fat mass and total body lean mass of rats that were not anesthetized, at indicated ages (EchoMRI-900; Hitachi).

ELISA for GLP-1. Anti-GLP-1 mAbs (GLIT2-863.35-7 and GLIT41448.7) were generated from Balb/c mice immunized with GLP-1-BSA. These mAb pairs were screened for specificity to total GLP-1 in plasma and serum. Conventional sandwich ELISAs were established in a 96-well plate using these mAb pairs. GLP-1 (7-36) amide (PEPTIDE INSTITUTE, INC., Osaka, Japan) was used as a reference standard for the assay. The detection limit of this assay was $0.3-300 \mathrm{pmol} / \mathrm{l}$; intra-assay and interassay variations were $\leq 15 \%$.

Statistical Analysis. Statistical significance was first analyzed using Bartlett's test for homogeneity of variances, followed by the Williams' test $(P>0.05)$ and Shirley-Williams test $(P \leq 0.05)$ for dose-dependent studies, and Dunnett's test $(P>0.05)$ and Steel test $(P \leq 0.05)$ for multiple comparisons. Alternatively, statistical significance was analyzed using the $F$ test for homogeneity of variances, followed by Student's $t$ test $(P>0.2)$ or the Aspin-Welch test $(P \leq 0.2)$. The Williams' and Shirley-Williams tests were conducted using a onetailed significance level of 2.5\% (0.025). Other tests were conducted using a two-tailed significance level of $5 \%(0.05)$. The $\mathrm{EC}_{50}$ and maximum effect $\left(E_{\max }\right)$ values were calculated using the four-parameter logistic equation in Prism 7 software (GraphPad Software, San Diego, CA). All data are presented as mean \pm S.D. (for in vivo experiments) or mean \pm S.E.M. (for in vitro experiments).

\section{Results}

SCO-267 Is a GPR40 Full Agonist that Stimulates Insulin and GLP-1 Secretions in Cells. We identified SCO-267 as a new GPR40 agonist (Fig. 1A), and compound profiles were determined by in vitro experiments. We used CHO cells expressing high (clone 104) or low (clone 2) levels of human FFAR1 to evaluate the agonistic activity of SCO-267 on $\mathrm{Ca}^{2+}$ response. SCO-267 showed $\mathrm{EC}_{50}$ values of $1.3 \mathrm{nmol} / \mathrm{l}$ (clone 104) and $12 \mathrm{nmol} / /$ (clone 2 ) and $E_{\max }$ values (percentage of $\gamma$-linolenic acid, an endogenous ligand) of $125 \%$ (clone 104) and 201\% (clone 2) (Fig. 1, B and C; Table 1). AM-1638 (Brown et al., 2012), a well-known GPR40 full agonist, had $\mathrm{EC}_{50}$ values of $7.1 \mathrm{nmol} / /$ (clone 104 ) and $150 \mathrm{nmol} / /$ (clone 2 ) and $E_{\max }$ values (percentage of $\gamma$-linolenic acid) of $110 \%$ (clone 104) and $182 \%$ (clone 2) (Fig. 1, B and C; Table 1). The insulinotropic effect of SCO-267 was examined in mouse insulinoma MIN6 cells. SCO-267 effectively stimulated insulin secretion under the high-glucose condition, unlike fasiglifam $\left[\mathrm{EC}_{50}=0.85 \mathrm{nmol} / \mathrm{l}\right.$ for SCO-267 and $\mathrm{EC}_{50}=530 \mathrm{nmol} / \mathrm{l}$ for fasiglifam; $E_{\max }$ (percentage of fasiglifam), $142 \%$ for SCO-267] (Fig. 1D). When tested in mouse enteroendocrine GLUTag cells, SCO-267 stimulated GLP-1 secretion by more than 4 -fold $\left(\mathrm{EC}_{50}=8.5 \mathrm{nmol} / \mathrm{l}\right)$ the level observed upon treatment with dimethylsulfoxide.

TABLE 2

In vitro plasma protein binding ratios of SCO-267 in rats, dogs, and humans

The mean of three samples is presented. Matrices shown are pooled plasma samples of 20 male Sprague-Dawley rats ( 8 weeks old), pooled plasma samples of 10 male beagles (10 months old), and pooled plasma samples of 10 male and 10 female humans.

\begin{tabular}{lcc}
\hline Matrix & Concentration of Compounds & Binding Ratio \\
\hline \multirow{4}{*}{ Rat } & $\mu g / m l$ & $\%$ \\
& 0.05 & 99.6 \\
\multirow{2}{*}{ Dog } & 0.5 & 99.6 \\
& 5 & 99.6 \\
Human & 0.05 & 99.6 \\
& 0.5 & 99.7 \\
& 5 & 99.7 \\
& 0.05 & 99.7 \\
& 0.5 & 99.7 \\
& 5 & 99.7 \\
\hline
\end{tabular}




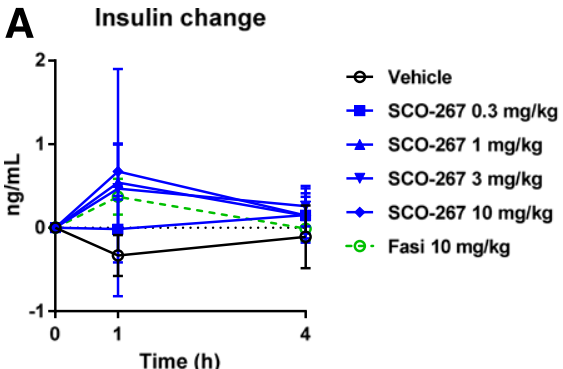

Insulin change $\mathrm{AUC}_{0-4 \mathrm{~h}}$

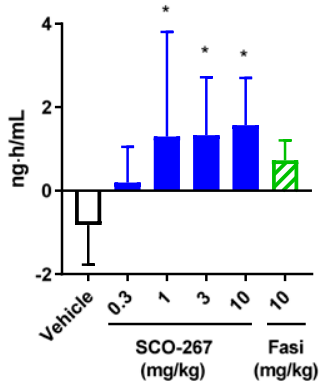

D

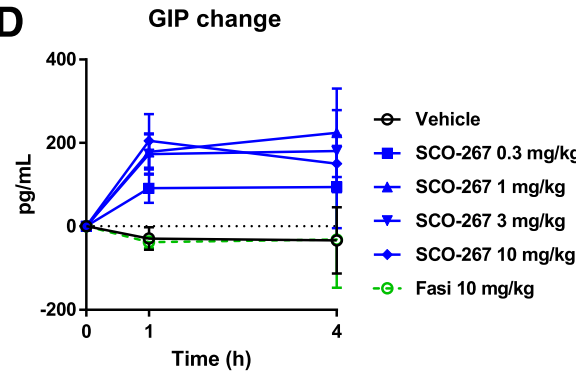

GIP change $A C_{0-4 h}$

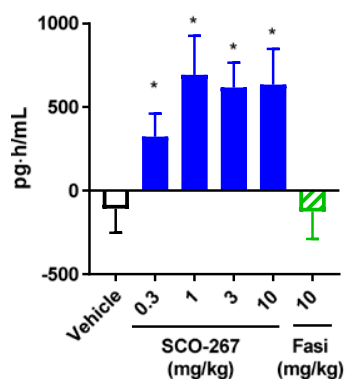

B

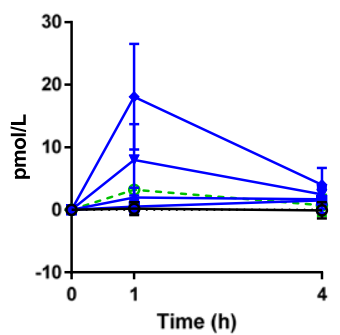

Glucagon change $\mathrm{AUC}_{0-4 h}$

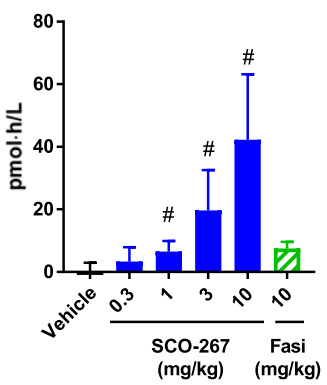

E

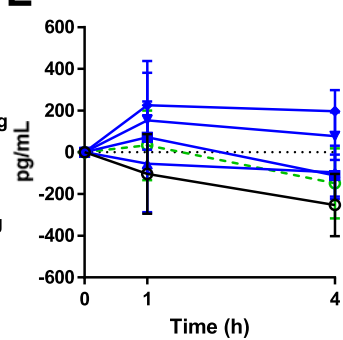

PYY change $A \mathrm{CC}_{0-4 \mathrm{~h}}$

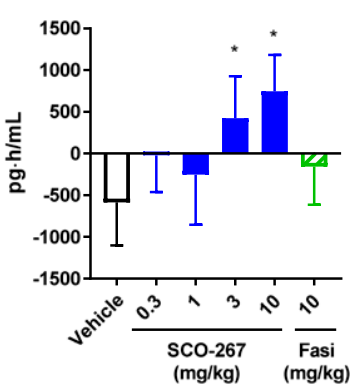

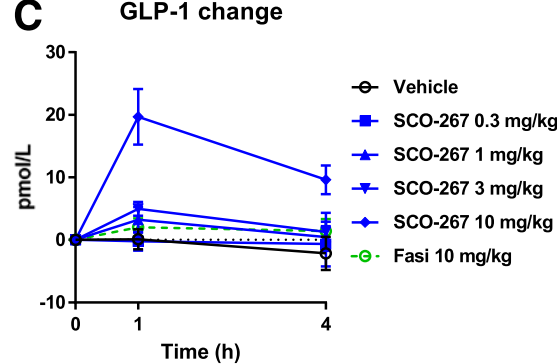

GLP-1 change $A \mathrm{CC}_{0-4 \mathrm{~h}}$

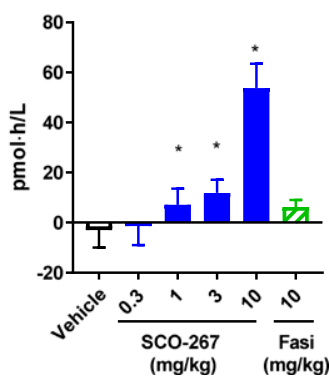

Fig. 2. Effect of a single dosing of SCO-267 on hormone secretion and fasting glucose in normal rats. Plasma levels of insulin (A), glucagon (B), GLP-1 (C), GIP (D), and PYY (E) in SCO-267-administered nonfasting normal rats. (F) Effects on fasting plasma glucose levels in overnight-fasted normal rats SCO-267 increased insulin, glucagon, GLP-1, GIP, and PYY levels in nonfasting normal rats. When administered to fasted normal rats, SCO-267 did not induce hypoglycemia, which was defined as plasma glucose levels $<70 \mathrm{mg} / \mathrm{dl}$ in this experiment. $* P<0.025$ and $\# P<0.025$ vs. vehicle by one-tailed Williams' test and Shirley-Williams test, respectively. Values are presented as mean \pm S.D. $(n=6)$. Fasi, fasiglifam.

SCO-267 was also more effective than $10 \mu \mathrm{mol} / \mathrm{l}$ fasiglifam (Fig. 1E). These data indicate that SCO-267 has full agonistic activity against GPR40. SCO-267 showed 99.6\%-99.7\% plasma protein binding ability in rats, dogs, and humans (Table 2).

SCO-267 Stimulates Secretion of Islet and Enteroendocrine Hormones and Does Not Induce Hypoglycemia in Normal Rats. In the nonfasting condition, SCO-267 (0.3-10 $\mathrm{mg} / \mathrm{kg})$ administration stimulated the secretion of insulin, glucagon, GLP-1, GIP, and PYY (Fig. 2, A-E). Fasiglifam $(10 \mathrm{mg} / \mathrm{kg})$ was not effective in inducing these hormonal changes (Fig. 2, A-E). Administration of glimepiride, a sulfonylurea class antidiabetic drug (Korytkowski, 2004), at $10 \mathrm{mg} / \mathrm{kg}$ induced overt hypoglycemia, with plasma glucose concentrations below $70 \mathrm{mg} / \mathrm{dl}$, in fasting rats. Although SCO-267 slightly decreased fasting plasma glucose levels, it did not induce hypoglycemia in normoglycemic rats (Fig. 2F). Pharmacokinetics analysis showed that a $0.3 \mathrm{mg} / \mathrm{kg}$ oral dose of SCO-267 resulted in a $C_{\max }$ value of $5.34 \mathrm{ng} / \mathrm{ml}$, time to reach maximum plasma concentration of 4.0 hours, area under the curve from zero to 24 hours $\left(\mathrm{AUC}_{0-24 \mathrm{~h}}\right.$ ) of $59.4 \mathrm{ng} \cdot \mathrm{h} / \mathrm{ml}$, and bioavailability of $24.8 \%$ in normal rats (Supplemental Fig. 1). 
Single dosing study

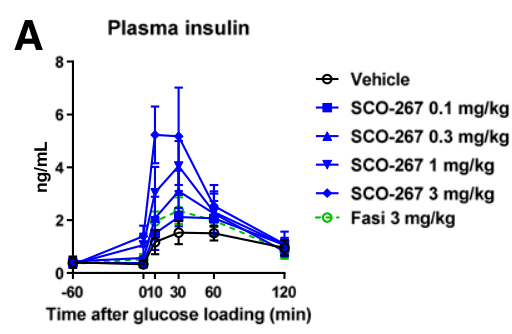

B Plasma GLP-1 change
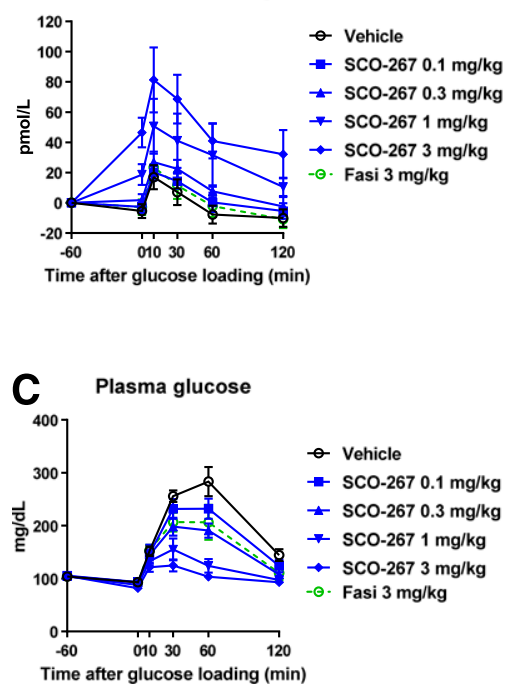
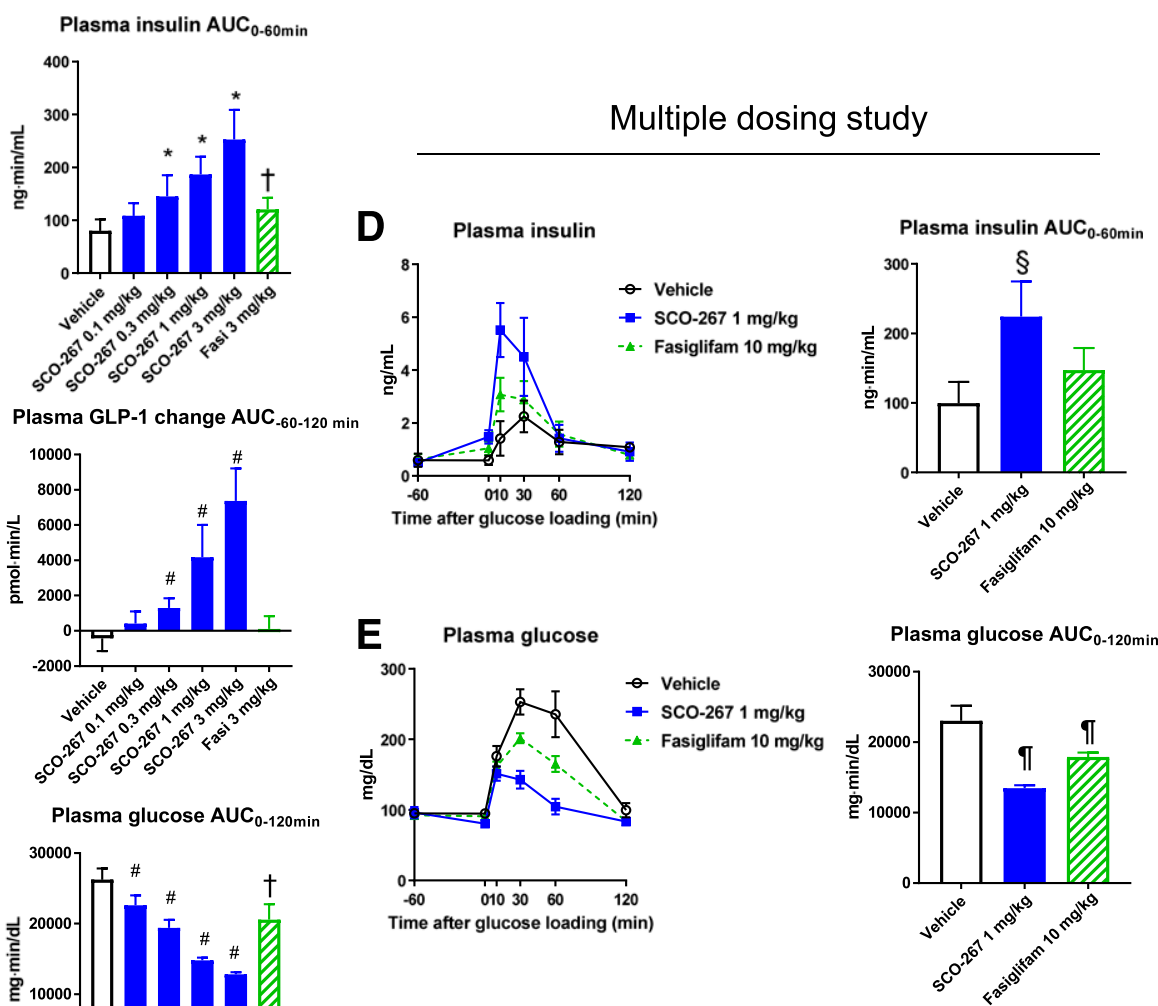

Fig. 3. Effects of single and repeated administration of SCO-267 on hormone secretion and glucose control in diabetic N-STZ-1.5 rats. Plasma insulin (A), GLP-1 (B), and glucose levels (C) in a single-dosing study with N-STZ-1.5 rats. Plasma levels of insulin (D) and glucose (E) after 2 weeks of repeateddosing with SCO-267 in N-STZ-1.5 rats. In a single dosing study, SCO-267 increased insulin levels, stimulated GLP-1 secretion, and improved glucose tolerance. Enhanced insulin secretion and improved glucose tolerance were maintained after the 2-week repeated administration of SCO-267. ${ }^{*} P<0.025$ and $\# P<0.025$ vs. vehicle by one-tailed Williams' test and one-tailed Shirley-Williams test, respectively. $\dagger P<0.05$ vs. vehicle by Student's $t$ test. $\S P<0.05$ and $\uparrow P<0.05$ vs. vehicle by Dunnett's test and Steel test, respectively. Values are presented as mean \pm S.D. $(n=6)$. Fasi, fasiglifam.

SCO-267 Improves Glucose Tolerance and Its Efficacy Is Durable in Diabetic Rats. A single oral administration of SCO-267 (0.1, 0.3, 1, and $3 \mathrm{mg} / \mathrm{kg})$ increased plasma insulin and GLP-1 levels and improved glucose tolerance after an oral glucose load in N-STZ-1.5 rats in a dose-dependent manner (Fig. 3, A-C). SCO-267 $(0.3 \mathrm{mg} / \mathrm{kg})$ and fasiglifam $\left(3 \mathrm{mg} / \mathrm{kg}\right.$ ) had $C_{\max }$ values of $22.7 \mathrm{ng} / \mathrm{ml}$ and $6.17 \mu \mathrm{g} / \mathrm{ml}$, respectively, in N-STZ-1.5 rats. The efficacy of SCO-267 was also compared with AM-1638 (Luo et al., 2012), a well-studied GPR40 full agonist, in N-STZ-1.5 rats. As shown in Supplemental Fig. 2, a lower plasma exposure of SCO-267 was more effective in enhancing insulin secretion and improving glucose tolerance compared with those by AM-1638 in N-STZ-1.5 rats. To test the efficacy and durability, SCO-267 $(1 \mathrm{mg} / \mathrm{kg})$ was repeatedly administered to N-STZ-1.5 rats for 2 weeks. Consistent with the single dosing efficacy, SCO-267 increased insulin secretion and improved glucose tolerance in N-STZ-1.5 rats after 2 weeks of repeated dosing (Fig. 3, D and E). At the end of the study, SCO-267 $(1 \mathrm{mg} / \mathrm{kg})$ had a $C_{\max }$ value of $139 \mathrm{ng} / \mathrm{ml}$ and $\mathrm{AUC}_{0-24} \mathrm{~h}$ of $626 \mathrm{ng} \cdot \mathrm{h} / \mathrm{ml}$, and fasiglifam $(10 \mathrm{mg} / \mathrm{kg}) \mathrm{had}$ a $C_{\max }$ value of $39.8 \mu \mathrm{g} / \mathrm{ml}$ and $\mathrm{AUC}_{0-24 \mathrm{~h}}$ of $255 \mu \mathrm{g} \cdot \mathrm{h} / \mathrm{ml}$ in N-STZ-1.5 rats (Supplemental Fig. 3). Food intake and body weight were unaltered in SCO-267-administered N-STZ-1.5 rats (Supplemental Fig. 4).

SC0-267 Elevates Circulating Gut Hormone and Decreases Body Weight in DIO Rats. The chronic effect of SCO-267 $(0.3-3 \mathrm{mg} / \mathrm{kg})$ was evaluated in obese rats that were fed a high-fat diet. After chronic dosing, GLP-1 and PYY levels were elevated after 16 hours of SCO-267 dosing (Fig. 4, A and B). During the experimental period, food intake levels were lower and total food intake was decreased in SCO-267-treated rats (Fig. 4, C and D). Consistent with the reduction in food intake, body weight and fat mass were decreased in SCO-267-treated rats (Fig. 4, E and F). The lean mass of SCO-267-treated DIO rats did not change. Plasma levels of glucose, triglycerides, alanine aminotransferase, and aspartate aminotransferase remained the same, whereas total cholesterol was reduced in SCO-267-treated DIO rats (Table 3). Pharmacokinetic analysis confirmed that sustained exposure to SCO-267 was effective in inducing these efficacies in DIO rats (Supplemental Fig. 5).

SCO-267 Induces GLP-1 Secretion and Food Intake Inhibition in a GPR40-Dependent Manner. Based on the pharmacokinetic data of the relatively short half-life of 


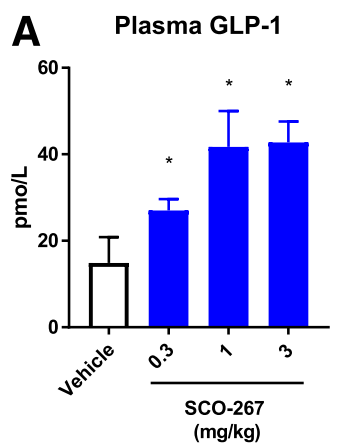

C

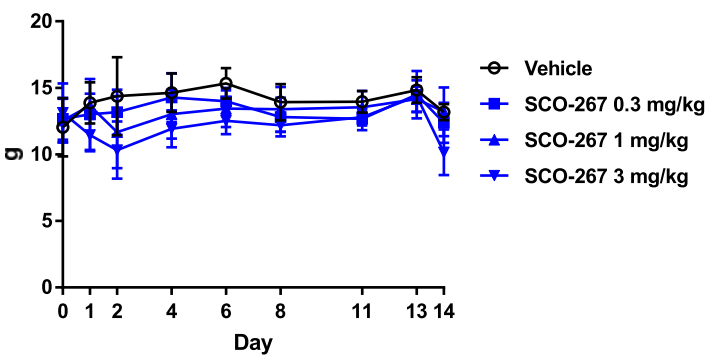

E

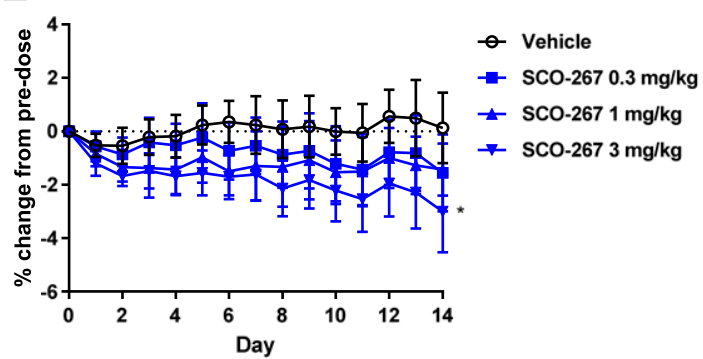

B

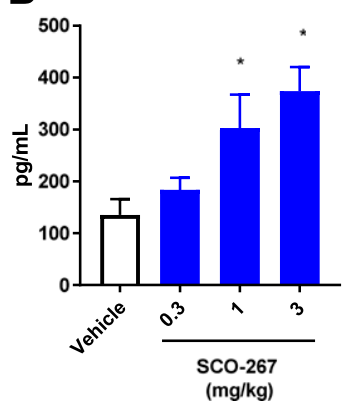

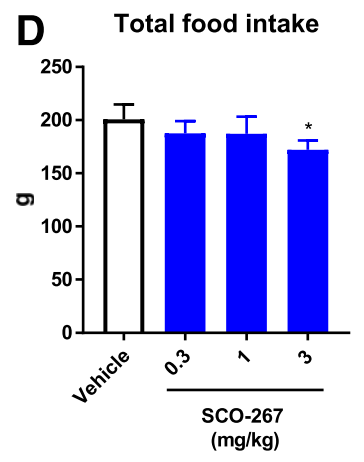

F Fat mass change

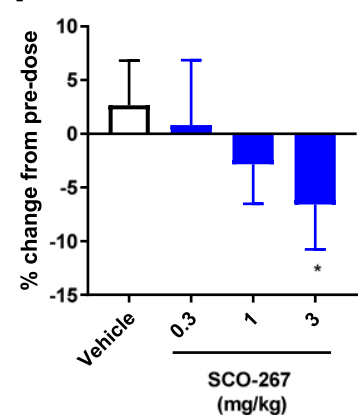

Fig. 4. Effects of SCO-267 on gut hormone secretion and body weight control in DIO rats. Plasma levels of GLP-1 (A), PYY (B), daily food intake (C), total food intake (D), body weight change (E), and fat mass change (F) in DIO rats. SCO-267 increased plasma GLP-1 and PYY after 2 weeks of treatment. Food intake was inhibited, and body weight was decreased by SCO-267 treatment. Fat mass was decreased in SCO-267-administered rats. ${ }^{*} P<0.025$ vs. vehicle by one-tailed Williams' test. Values are presented as mean \pm S.D. $(n=6)$.

SCO-267 in mice (Supplemental Fig. 6), we used $30 \mathrm{mg} / \mathrm{kg}$ as the oral SCO-267 dose in a mouse study. In WT mice, SCO-267 stimulated GLP-1 secretion, inhibited food intake, and reduced body weight (Fig. 5). In contrast, SCO-267 did not induce GLP-1 secretion, food intake inhibition, and body weight reduction in $F$ far $1^{-/-}$mice (Fig. 5).

\section{Discussion}

In this study, we demonstrated that SCO-267, a new GPR40 agonist, was highly effective in activating GPR40 and improving glucose control in vivo. The in vitro experiments confirmed the stimulatory effect of SCO-267 on $\mathrm{Ca}^{2+}$ signaling, insulin release, and GLP-1 secretion in FFAR1-expressing CHO, MIN6, and GLUTag cells, respectively. When tested in normal rats, SCO-267 stimulated the secretion of hormones from the islet and gut. These results demonstrate the full agonistic property of SCO-267 against GPR40. Hypoglycemia was not induced in rats during the fasting condition. Studies in N-STZ-1.5 rats with diabetes confirmed the efficacy of SCO-267 in improving glucose control, and the durability of this effect. SCO-267 was also effective in decreasing body weight in DIO rats, which may have been via a GPR40-dependent mechanism. The data suggest that SCO-267 has potential as a novel therapeutic agent for treating diabetes and obesity.

In a single dosing study of N-STZ-1.5 rats, $0.3 \mathrm{mg} / \mathrm{kg}$ SCO$267\left(C_{\max }=22.7 \mathrm{ng} / \mathrm{ml}\right)$ had a glucose-lowering efficacy comparable to that of $3 \mathrm{mg} / \mathrm{kg}$ fasiglifam $\left(C_{\max }=6.17 \mu \mathrm{g} / \mathrm{ml}\right)$. This indicated that a substantially lower compound exposure is sufficient for inducing the efficacy of SCO-267. In a repeated-dosing study of N-STZ-1.5 rats, $1 \mathrm{mg} / \mathrm{kg}$ SCO-267 $\left(C_{\max }=139 \mathrm{ng} / \mathrm{ml} ; \mathrm{AUC}_{0-24 \mathrm{~h}}=626 \mathrm{ng} \cdot \mathrm{h} / \mathrm{ml}\right)$ was more effective in improving glucose tolerance than $10 \mathrm{mg} / \mathrm{kg}$ fasiglifam $\left(C_{\max }=39.8 \mu \mathrm{g} / \mathrm{ml} ; \mathrm{AUC}_{0-24 \mathrm{~h}}=255 \mu \mathrm{g} \cdot \mathrm{h} / \mathrm{ml}\right)$. Plasma protein binding of SCO-267 was similar across species (99.6\%-99.7\%), and fasiglifam showed similar plasma protein binding across species ( $>99.4 \%$ for fasiglifam (Kogame et al., 2019)). With the clinically effective exposure of $50 \mathrm{mg}$ fasiglifam $\left(C_{\max }=5.3 \mu \mathrm{g} / \mathrm{ml} ; \mathrm{AUC}_{0-24 \mathrm{~h}}=100.3 \mu \mathrm{g} \cdot \mathrm{h} / \mathrm{ml}\right)$ (Leifke et al., 2012), SCO-267 may be effective in improving glucose control in patients with type 2 diabetes. Additionally, the lower plasma exposure to SCO-267 may be a safety advantage compared with exposure to fasiglifam, which was voluntarily terminated in phase 3 due to possible adverse effects on the liver.

SCO-267 robustly stimulated insulin secretion in dysfunctional $\beta$-cells in N-STZ-1.5 rats. In addition, SCO-267 stimulated 
TABLE 3

Plasma metabolic parameters in SCO-267-treated DIO rats

$* P<0.025$ vs. vehicle by one-tailed Williams' test. $n=6$, mean \pm S.D.

\begin{tabular}{lccccc}
\hline \multicolumn{1}{c}{ Dosage } & Glucose & Triglyceride & Total Cholesterol & Alanine Aminotransferase & Aspartate Aminotransferase \\
\hline & $m g / d l$ & $m g / d l$ & $m g / d l$ & $U / l$ & $U / l$ \\
Vehicle & $119 \pm 10$ & $296 \pm 98$ & $117 \pm 17$ & $42 \pm 8$ & $74 \pm 29$ \\
SCO-267 $(0.3 \mathrm{mg} / \mathrm{kg})$ & $120 \pm 2$ & $271 \pm 63$ & $109 \pm 8$ & $48 \pm 15$ & $61 \pm 13$ \\
SCO-267 $(1 \mathrm{mg} / \mathrm{kg})$ & $116 \pm 14$ & $242 \pm 75$ & $100 \pm 12^{*}$ & $45 \pm 10$ & $64 \pm 10$ \\
SCO-267 $(3 \mathrm{mg} / \mathrm{kg})$ & $118 \pm 9$ & $261 \pm 106$ & $102 \pm 10^{*}$ & $47 \pm 8$ & $62 \pm 8$ \\
\hline
\end{tabular}

the secretion of GLP-1 and GIP, both of which are incretin hormones having insulinotropic action (Nauck and Meier, 2018). Taken together with the direct insulinotropic effect on $\beta$-cells expressing Ffar 1 , increased secretion of GLP-1 and GIP may have contributed to the enhanced insulin secretion observed in SCO-267-administered rats.

We compared the efficacy of SCO-267 to AM-1638, a wellstudied GPR40 full agonist. The in vitro experiment showed that $\mathrm{Ca}^{2+}$ influx activity of SCO-267 was 5.5- to 12.5 -fold more potent compared with AM-1638 in human FFAR1-expressing $\mathrm{CHO}$ cells. When each compound was orally dosed at the same dosage levels, SCO-267 was more effective in improving glucose tolerance compared with AM-1638 in N-STZ-1.5 rats. These results indicate that SCO-267 is a potent GPR40 full agonist. Considering the lower plasma exposure of SCO267 in inducing efficacy and good pharmacokinetic profiles, SCO-267 is likely a good candidate for testing in clinical trials.

When a GPCR is exposed to its agonist over a period of minutes to hours or days, the response is significantly reduced and is associated with decreased receptor expression at the plasma membrane. This process is referred to as downregulation (Zhang et al., 2014; Rajagopal and Shenoy, 2018). Some GPCRs undergo receptor desensitization after repeated stimulation, thus decreasing and in some cases abolishing the biologic response to a drug (Zhang et al., 2014; Rajagopal and Shenoy, 2018). In diabetes and obesity, sustained efficacy is important for a drug targeting GPCRs to induce therapeutic benefits. In the present study, 2 weeks of repeated dosing of SCO-267 resulted in sustained glucose lowering, and the efficacy was much better than that of fasiglifam in N-STZ-1.5 rats. This suggests that the efficacy of SCO-267 is strong and durable. Although the agonism of fasiglifam is partial, it has shown effectiveness in decreasing $\mathrm{HbA1c}$ levels in a 52-week study of patients with type 2 diabetes (Kaku et al., 2016). Therefore, SCO-267 may induce similar durability and better efficacy in humans.

Food intake was diminished, and body weight was lowered in SCO-267-treated DIO rats. Plasma GLP-1 and PYY levels remained high 16 hours after the final dose was administered to DIO rats. Considering the elevated levels of GLP-1 and PYY, both of which are physiologic hormones regulating satiety and body weight (Moran, 2006; Troke et al., 2014), these hormones may have contributed to the body weight reduction observed in SCO-267-administered DIO rats. In addition, sustained plasma exposure of SCO-267 was confirmed in DIO rats with reduced body weight, suggesting that the efficacy is durable. SCO-267-induced GLP-1 secretion and food intake inhibition were observed in WT mice and were abolished in $F$ far $1^{-1-}$ mice. This suggests that the aforementioned processes are controlled by GPR40dependent mechanisms. Although a further study is essential to elucidate the mechanism by which GPR40 agonism regulates food intake and body weight, this property of SCO267 may be beneficial in patients who are overweight or obese and have type 2 diabetes.

SCO-267 stimulated glucagon secretion in rats, which is consistent with a previous study using a GPR40 full agonist (Pachanski et al., 2017). This suggests that GPR40 full agonists exhibit a direct targeted effect on glucagon secretion. Glucagon has pleiotropic physiologic effects in the body as evidenced by the high expression of its receptors in the liver and low expression in the kidneys, adipose tissue,
A

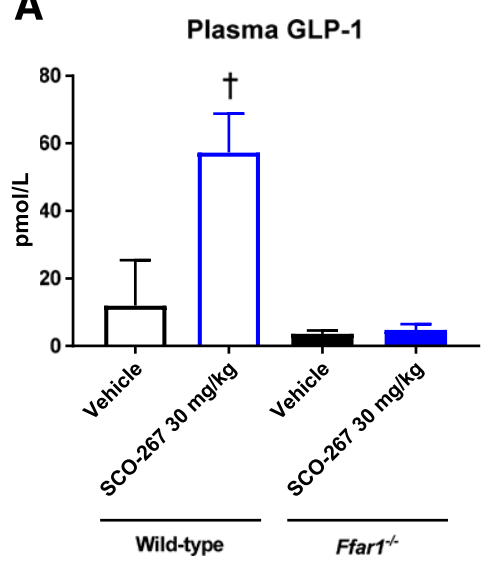

B

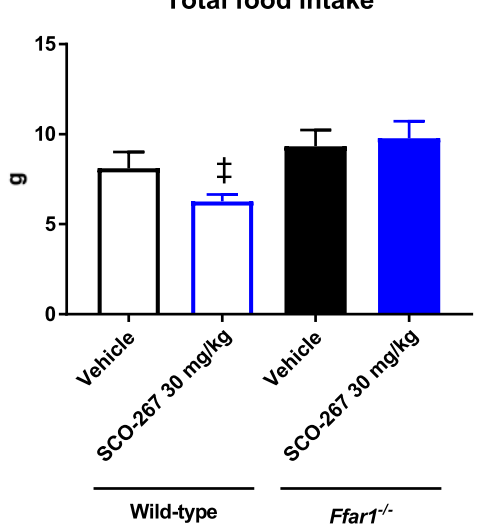

C

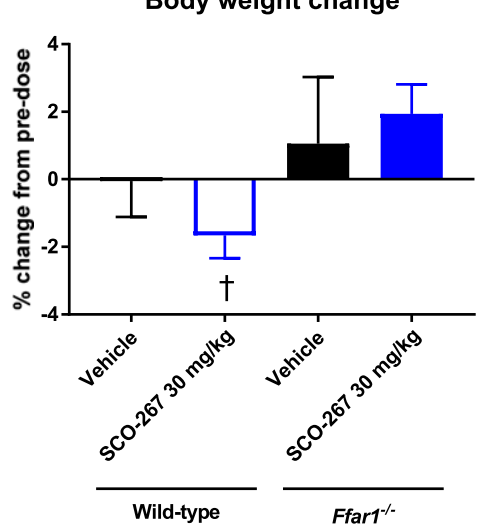

Fig. 5. Effects of SCO-267 on GLP-1, food intake, and body weight in $F f a r 1^{-/-}$mice. GLP-1 levels (A), food intake (B), and body weight change (C). WT and $\mathrm{Ffar}^{-1-}$ mice were treated with either vehicle or SCO-267 $(30 \mathrm{mg} / \mathrm{kg})$ for 3 to 4 days. SCO-267 increased plasma GLP-1, decreased total food intake, and decreased body weight in WT mice, whereas these effects were abolished in $F f a r 1^{-1}$ mice. $\dagger P<0.05$ and $\ddagger P<0.05$ vs. vehicle-treated WT mice by Student's $t$ test and the Aspin-Welch test, respectively. Values are presented as mean \pm S.D. $(n=6)$. 
lymphoblasts, spleen, pancreas, brain, adrenal glands, and gastrointestinal tract (Svoboda et al., 1994). In addition to its pivotal role in hepatic glucose metabolism, glucagon regulates hepatic fat metabolism promoting lipid oxidation and lowering lipid synthesis (Seghieri et al., 2018). It is well established that nonalcoholic fatty liver disease is common among individuals with type 2 diabetes, and increases the risk of diabetes and diabetic complications (Hazlehurst et al., 2016). Therefore, the activation of liver glucagon signaling, which decreases hepatic lipid, may improve hepatocyte function. Furthermore, a study suggested that glucagon receptor signaling is essential in the control of murine hepatocyte survival (Sinclair et al., 2008). Glucagon signaling activation has also been suggested to exert antiapoptotic actions in the liver (Sinclair et al., 2008). Therefore, glucagon signaling activation may be beneficial in treating liver diseases such as nonalcoholic fatty liver disease and more advanced nonalcoholic steatohepatitis. In fact, the addition of glucagon agonism to GLP-1 receptor agonism improved lipid metabolism and hepatic steatosis when compared with GLP-1 receptor agonism alone in rodents (Day et al., 2009). However, the contribution of SCO-267-induced glucagon stimulation to liver health requires further studies.

In conclusion, the GPR40 full agonist, SCO-267, stimulated insulin, glucagon, GLP-1, GIP, and PYY secretion. Furthermore, SCO-267 effectively improved glucose control and exerted strong efficacy in rats with diabetes. In addition, body weight loss was observed in obese rats. Thus, SCO-267 is effective in improving diabetes and obesity in rats and may induce similar favorable effects in patients with diabetes and obesity.

\section{Acknowledgments}

MIN6 murine pancreatic $\beta$-cell cells and GLUTag intestinal L-cells were kindly provided by Jun-ichi Miyazaki (Osaka University) and Daniel J. Drucker (University of Toronto), respectively. We thank Ikumi Chisaki for measuring the pharmacokinetics parameters and Seigo Izumo for valuable discussions and helpful suggestions. We gratefully acknowledge Tomofumi Kurokawa, Yukio Toyoda, Yoshitaka Yasuhara, Naoyoshi Noguchi, Toshitake Kobayashi, Toshikazu Ando, and Masahiro Ide for support.

\section{Authorship Contributions}

Participated in research design: Ueno, Ito, Abe, Ookawara, Miyashita, Ogino, Miyamoto, Yoshihara, Kobayashi, Tsujihata, Takeuchi, Watanabe, Yamada, Maekawa, Nishigaki, Moritoh.

Conducted experiments: Ueno, Ito, Abe, Ookawara, Miyashita, Ogino, Kobayashi, Moritoh.

Contributed new reagents or analytic tools: Miyamoto, Yoshihara, Maekawa.

Performed data analysis: Ueno, Ito, Abe, Ookawara, Miyashita, Ogino, Miyamoto, Yoshihara, Kobayashi, Tsujihata, Takeuchi, Watanabe, Yamada, Maekawa, Nishigaki, Moritoh.

Wrote or contributed to the writing of the manuscript: Ueno, Nishigaki, Moritoh.

\section{References}

Aida J, Yoshitomi Y, Hitomi Y, Noguchi N, Hirata Y, Furukawa H, Shibuya A, Watanabe K, Miyamoto Y, Okawa T, et al. (2015) ALOMATIC COMPOUND, WO 2015/020184.

American Diabetes Association (2018) 14. Diabetes care in the hospital: standards of medical care in diabetes-2018. Diabetes Care 41 (Suppl 1):S144-S151.

Briscoe CP, Tadayyon M, Andrews JL, Benson WG, Chambers JK, Eilert MM,

Ellis C, Elshourbagy NA, Goetz AS, Minnick DT, et al. (2003) The orphan G protein-coupled receptor GPR40 is activated by medium and long chain fatty acids. J Biol Chem 278:11303-11311.
Brown SP, Dransfield PJ, Vimolratana M, Jiao X, Zhu L, Pattaropong V, Sun Y, Liu J, Luo J, Zhang J, et al. (2012) Discovery of AM-1638: a potent and orally bioavailable GPR40/FFA1 full agonist. ACS Med Chem Lett 3:726-730.

Burant CF, Viswanathan P, Marcinak J, Cao C, Vakilynejad M, Xie B, and Leifke E (2012) TAK-875 versus placebo or glimepiride in type 2 diabetes mellitus: a phase 2, randomised, double-blind, placebo-controlled trial. Lancet $\mathbf{3 7 9}$ 1403-1411.

Day JW, Ottaway N, Patterson JT, Gelfanov V, Smiley D, Gidda J, Findeisen H, Bruemmer D, Drucker DJ, Chaudhary N, et al. (2009) A new glucagon and GLP-1 co-agonist eliminates obesity in rodents. Nat Chem Biol 5:749-757.

Defossa E and Wagner M (2014) Recent developments in the discovery of FFA1 receptor agonists as novel oral treatment for type 2 diabetes mellitus. Bioorg Med Chem Lett 24:2991-3000.

Eleazu C, Charles A, Eleazu K, and Achi N (2018) Free fatty acid receptor 1 as a novel therapeutic target for type 2 diabetes mellitus-current status. Chem Biol Interact 289:32-39.

Ghislain J and Poitout V (2017) The role and future of FFA1 as a therapeutic target. Handb Exp Pharmacol 236:159-180.

Hazlehurst JM, Woods C, Marjot T, Cobbold JF, and Tomlinson JW (2016) Nonalcoholic fatty liver disease and diabetes. Metabolism 65:1096-1108.

Ito R, Tsujihata Y, Matsuda-Nagasumi K, Mori I, Negoro N, and Takeuchi K (2013) TAK-875, a GPR40/FFAR1 agonist, in combination with metformin prevents progression of diabetes and $\beta$-cell dysfunction in Zucker diabetic fatty rats. $\mathrm{Br} J$ Pharmacol 170:568-580.

Itoh Y, Kawamata Y, Harada M, Kobayashi M, Fujii R, Fukusumi S, Ogi K, Hosoya M, Tanaka Y, Uejima H, et al. (2003) Free fatty acids regulate insulin secretion from pancreatic $\beta$ cells through GPR40. Nature 422:173-176.

Kaku K, Araki T, and Yoshinaka R (2013) Randomized, double-blind, dose-ranging study of TAK-875, a novel GPR40 agonist, in Japanese patients with inadequately controlled type 2 diabetes. Diabetes Care 36:245-250.

Kaku K, Enya K, Nakaya R, Ohira T, and Matsuno R (2016) Long-term safety and efficacy of fasiglifam (TAK-875), a G-protein-coupled receptor 40 agonist, as monotherapy and combination therapy in Japanese patients with type 2 diabetes: a 52-week open-label phase III study. Diabetes Obes Metab 18: 925-929.

Kogame A, Lee R, Pan L, Sudo M, Nonaka M, Moriya Y, Higuchi T, and Tagawa Y (2019) Disposition and metabolism of the $\mathrm{G}$ protein-coupled receptor 40 agonist TAK-875 (fasiglifam) in rats, dogs, and humans. Xenobiotica 49:433-445.

Korytkowski MT (2004) Sulfonylurea treatment of type 2 diabetes mellitus: focus on glimepiride. Pharmacotherapy 24:606-620.

Kotarsky K, Nilsson NE, Olde B, and Owman C (2003) Progress in methodology. Improved reporter gene assays used to identify ligands acting on orphan seventransmembrane receptors. Pharmacol Toxicol 93:249-258.

Lee YC, Asa SL, and Drucker DJ (1992) Glucagon gene 5'-flanking sequences direct expression of simian virus 40 large $\mathrm{T}$ antigen to the intestine, producing carcinoma of the large bowel in transgenic mice. J Biol Chem 267:10705-10708.

Leifke E, Naik H, Wu J, Viswanathan P, Demanno D, Kipnes M, and Vakilynejad M (2012) A multiple-ascending-dose study to evaluate safety, pharmacokinetics, and pharmacodynamics of a novel GPR40 agonist, TAK-875, in subjects with type 2 diabetes. Clin Pharmacol Ther 92:29-39.

Li Z, Xu X, Huang W, and Qian H (2018) Free fatty acid receptor 1 (FFAR1) as an emerging therapeutic target for type 2 diabetes mellitus: recent progress and prevailing challenges. Med Res Rev 38:381-425.

Luo J, Swaminath G, Brown SP, Zhang J, Guo Q, Chen M, Nguyen K, Tran T, Miao L, Dransfield PJ, et al. (2012) A potent class of GPR40 full agonists engages the enteroinsular axis to promote glucose control in rodents. PLoS One 7:e46300.

Mancini AD and Poitout V (2013) The fatty acid receptor FFA1/GPR40 a decade later: how much do we know? Trends Endocrinol Metab 24:398-407.

Matsuda-Nagasumi K, Takami-Esaki R, Iwachidow K, Yasuhara Y, Tanaka H, Ogi K, Nakata M, Yano T, Hinuma S, Taketomi S, et al. (2013) Lack of GPR40/ FFAR1 does not induce diabetes even under insulin resistance condition. Diabetes Obes Metab 15:538-545.

Miyazaki J, Araki K, Yamato E, Ikegami H, Asano T, Shibasaki Y, Oka Y, and Yamamura K (1990) Establishment of a pancreatic $\beta$ cell line that retains glucose-inducible insulin secretion: special reference to expression of glucose transporter isoforms. Endocrinology 127:126-132.

Moran TH (2006) Gut peptide signaling in the controls of food intake. Obesity (Silver Spring) 14 (Suppl 5):250S-253S.

Nauck MA and Meier JJ (2018) Incretin hormones: their role in health and disease. Diabetes Obes Metab 20 (Suppl 1):5-21.

Nauck MA, Meier JJ, Cavender MA, Abd El Aziz M, and Drucker DJ (2017) Cardiovascular actions and clinical outcomes with glucagon-like peptide-1 receptor agonists and dipeptidyl peptidase-4 inhibitors. Circulation 136:849-870.

Negoro N, Sasaki S, Mikami S, Ito M, Suzuki M, Tsujihata Y, Ito R, Harada A Takeuchi K, Suzuki N, et al. (2010) Discovery of TAK-875: a potent, selective, and orally bioavailable GPR40 agonist. ACS Med Chem Lett 1:290-294.

Pachanski MJ, Kirkland ME, Kosinski DT, Mane J, Cheewatrakoolpong B, Xue J, Szeto D, Forrest G, Miller C, Bunzel M, et al. (2017) GPR40 partial agonists and AgoPAMs: differentiating effects on glucose and hormonal secretions in the rodent. PLoS One 12:e0186033.

Pais R, Gribble FM, and Reimann F (2016) Stimulation of incretin secreting cells Ther Adv Endocrinol Metab 7:24-42.

Portha B, Giroix M, Serradas P, Movassat J, Bailbe D, and Kergoat M (2003) The neonatally streptozotocin-induced (n-STZ) diabetic rats, a family of NIDDM models, in Animal Models in Diabetes, pp 223-250, CRC Press, Boca Raton, Florida.

Rajagopal S and Shenoy SK (2018) GPCR desensitization: acute and prolonged phases. Cell Signal 41:9-16.

Seghieri M, Christensen AS, Andersen A, Solini A, Knop FK, and Vilsbøll T (2018) Future perspectives on GLP-1 receptor agonists and GLP-1/glucagon receptor co-agonists in the treatment of NAFLD. Front Endocrinol (Lausanne) 9:649. 
Sinclair EM, Yusta B, Streutker C, Baggio LL, Koehler J, Charron MJ, and Drucker DJ (2008) Glucagon receptor signaling is essential for control of murine hepatocyte survival. Gastroenterology 135:2096-2106.

Svoboda M, Tastenoy M, Vertongen P, and Robberecht P (1994) Relative quantitative analysis of glucagon receptor mRNA in rat tissues. Mol Cell Endocrinol 105:131-137.

Troke RC, Tan TM, and Bloom SR (2014) The future role of gut hormones in the treatment of obesity. Ther Adv Chronic Dis 5:4-14.

Tsujihata Y, Ito R, Suzuki M, Harada A, Negoro N, Yasuma T, Momose Y, and Takeuchi K (2011) TAK-875, an orally available G protein-coupled receptor 40/ free fatty acid receptor 1 agonist, enhances glucose-dependent insulin secretion and improves both postprandial and fasting hyperglycemia in type 2 diabetic rats. $J$ Pharmacol Exp Ther 339:228-237.

Wolenski FS, Zhu AZX, Johnson M, Yu S, Moriya Y, Ebihara T, Csizmadia V, Grieves J, Paton M, Liao M, et al. (2017) Fasiglifam (TAK-875) alters bile acid homeostasis in rats and dogs: a potential cause of drug induced liver injury. Toxicol Sci 157: $50-61$.
Yabuki C, Komatsu H, Tsujihata Y, Maeda R, Ito R, Matsuda-Nagasumi K, Sakuma K, Miyawaki K, Kikuchi N, Takeuchi K, et al. (2013) A novel antidiabetic drug, fasiglifam/TAK-875, acts as an ago-allosteric modulator of FFAR1. PLoS One 8: e76280.

Zhang SY, Li J, and Xie X (2014) Discovery and characterization of novel small molecule agonists of G protein-coupled receptor 119. Acta Pharmacol Sin 35: 540-548.

Address correspondence to: Yusuke Moritoh, Research and Development Division, SCOHIA PHARMA, Inc., 26-1, Muraoka-Higashi 2-chome, Fujisawa, Kanagawa 251-8555, Japan. E-mail: yusuke.moritoh@scohia.com; or Nobuhiro Nishigaki, Therapeutic Area General Medicine, Japan Medical Office, Takeda Pharmaceutical Company Limited. 1-1, Nihonbashi-Honcho 2-Chome, Chuoku, Tokyo 103-8686, Japan. E-mail: nobuhiro.nishigaki@takeda.com 